\title{
Feasibility and Advantages of Transanal Minimally Invasive Surgery (TAMIS) for Various Lesions in the Rectum
}

\author{
Min Kyu Kang, MBBS, MSc, Rumi Shin, M.D., Beong-hoon Sohn, M.D., Seung-chul Heo, M.D., Ph.D. \\ Department of Surgery, Seoul Metropolitan Government-Seoul National University Boramae Medical Center, Seoul, Korea
}

Purpose: We report our experience in the use of transanal minimally invasive surgery (TAMIS) and the feasibility and safety of this surgical technique in operating for various rectal diseases that require a transanal approach.

Methods: Between 2013 and 2019, 30 patients underwent TAMIS for a rectal lesion at Seoul National University Boramae Medical Center. The clinical data including age, gender, body mass index, tumour size, distance from the anal verge, diagnosis, operation time, postoperative complications, duration of hospital stay, and post-operative margin status were obtained retrospectively from the electronic medical records.

Results: The mean operation time was $52.1 \pm 33.5$ and the mean duration of hospital stay after surgery was $4.3 \pm 4.2$ days. Most of the patients had undergone TAMIS for neuroendocrine tumor (NET) (60\%) followed by an adenoma (16.7\%) and rectal cancer (13.3\%). 4 patients (13.3\%) had minor complications after TAMIS. 2 patients $(50 \%)$ had complained of diarrhea, 1 patient $(25 \%)$ complained of fecal incontinence and 1 patient (25\%) been diagnosed fluid in the operation bed.

Conclusion: TAMIS is a useful method for local excision of rectal lesion located in mid to upper rectum as well as other rectal pathologies that require a transanal approach.
Received September 4, 2019

Revised October 11, 2019

Accepted October 21, 2019

Corresponding author

Rumi Shin

Department of Surgery, Seoul

Metropolitan Government-Seoul

National University Boramae

Medical Center, 20 Boramae-ro

5-gil, Dongjak-gu, Seoul 07061,

Korea

Tel: +82-2-870-3295

Fax: +82-2-831-0714

E-mail: roomie79@gmail.com

ORCID:

https://orcid.org/0000-0001-5500-8702

Keywords: Rectum, Minimally invasive surgical procedure, Neuroendocrine tumour, Transanal endoscopic microsurgery

This is an Open Access article distributed under the terms of the Creative Commons Attribution Non-Commercial License (http:// creativecommons.org/licenses/by-nc/4.0/) which permits unrestricted non-commercial use, distribution, and reproduction in any medium, provided the original work is properly cited.

\section{INTRODUCTION}

Transanal endoscopic microsurgery (TEM) is an advanced surgical technique for transanal excision (TAE) for early rectal cancer or benign rectal lesions. ${ }^{1}$ It was introduced to overcome the drawback of conventional transanal excision such as the ease in securing the surgical field and reducing collision between instruments, ${ }^{2,3}$ and several studies showed TEM provided better surgical and oncological outcomes than conventional TAE $^{4-6}$ Despite superior outcomes of TEM in the literature, it has not been widely performed due to the complex learning curve, cost issue, specialized instrumentation and complication risks such as defective anorectal function after the surgery. ${ }^{7.8}$

Transanal minimally invasive surgery (TAMIS) is an emerging surgical technique to be an improvement to TEM as it can provide spacious surgical field by making pneumorectum, shorter learning curve of operation due to the use the conventional laparoscopic devices and lower costs as a result. ${ }^{9.10}$ In several studies, TAMIS has shown to be safe and effective for benign lesions and early-stage malignancy in the middle rectum. ${ }^{11,12}$ In this study, we report our experience in the use of TAMIS and assess the feasibility and safety of this surgical technique in operating for various rectal diseases that require a transanal approach. 


\section{MATERIALS AND METHODS}

\section{Study patients}

Between 2013 and 2019, 30 patients underwent TAMIS for a rectal lesion at Seoul National University Boramae Medical Center. Selection criteria for TAMIS included early rectal cancers without lymph node involvement, lateral spreading tumours that comprised less than $50 \%$ of the circumference, neuroendocrine tumours (NET), and incomplete resected adenoma or NET after endoscopic submucosal dissection (ESD) or endoscopic mucosal resection (EMR). Other patients with rectal pathology such as rectal sinus, rectal stenosis and anastomosis dehiscence were also candidates for TAMIS.

The clinical data including age, gender, body mass index (BMI), tumour size, distance from the anal verge (AV), diagnosis, operation time, postoperative complications, duration of hospital stay, and post-operative pathological margin status were obtained retrospectively from the electronic medical records. The study protocol was approved by the institutional review board of Seoul National University Boramae Medical Center (IRB number, 16-2016-117).

\section{Operative technique}

The procedure was carried out in the order of 'exposure', 'excision' and 'closure'. Patient was positioned in lithotomy position under general anasesthesia. Digital rectal examination with gentle anal dilatation prior to insertion of single-incision laparoscopic surgery port (SILS ${ }^{\mathrm{TM}}$ port; Medtronic, UK) was done and then the port was anchored with 1-0 vicryl suture on right anterior, left anterior, and posterior side of the anal canal. Then pneumorectum was made by $\mathrm{CO}_{2}$ gas inflation and maintained $18 \mathrm{mmHg}$ pressure and we used $5 \mathrm{~mm} \mathrm{30^{ \circ }}$ laparoscope to reduce the collision between instruments and optimize the view during the surgery. The inflation pressure of $18 \mathrm{mmHg}$ was decided with reference to previous study on the use of TAMIS on mid-rectal lesions. ${ }^{13}$

After the lesion is identified, it was grasped and lifted gently. The mucosa was marked by hook at least $0.5 \mathrm{~cm}$ away from lesion to achieve safety margin. Dissection was done from caudal to cranial approach and a Harmonic scalpel (Ethicon ${ }^{\circledR}$ ) was used to excise the rectal lesion down to mesorectal fat (Fig. 1). After complete detachment of proximal attachments, careful hemostasis and irrigation with normal saline were performed and the closure of the defect was accomplished by using ENDOLOOP ${ }^{\circledast}$.

\section{RESULTS}

\section{Patients characteristics}

Total of 30 patients (19 males and 11 females) were eligible for analysis. The analysis of patient characteristics is represented in Table 1. The mean age at surgery was $54.4 \pm 17.1$ years and mean BMI was $24.3 \pm 3.1$. The mean distance from the anal verge to the rectal lesion was $7.0 \pm 3.1 \mathrm{~cm}$ with a mean size of $1.6 \pm 1.6 \mathrm{~cm} .14$ patients (46.7\%) underwent endoscopic resection prior to operation, of which 10 (71.4\%) received EMR and $4(28.6 \%)$ received ESD. Most of the patients had under-
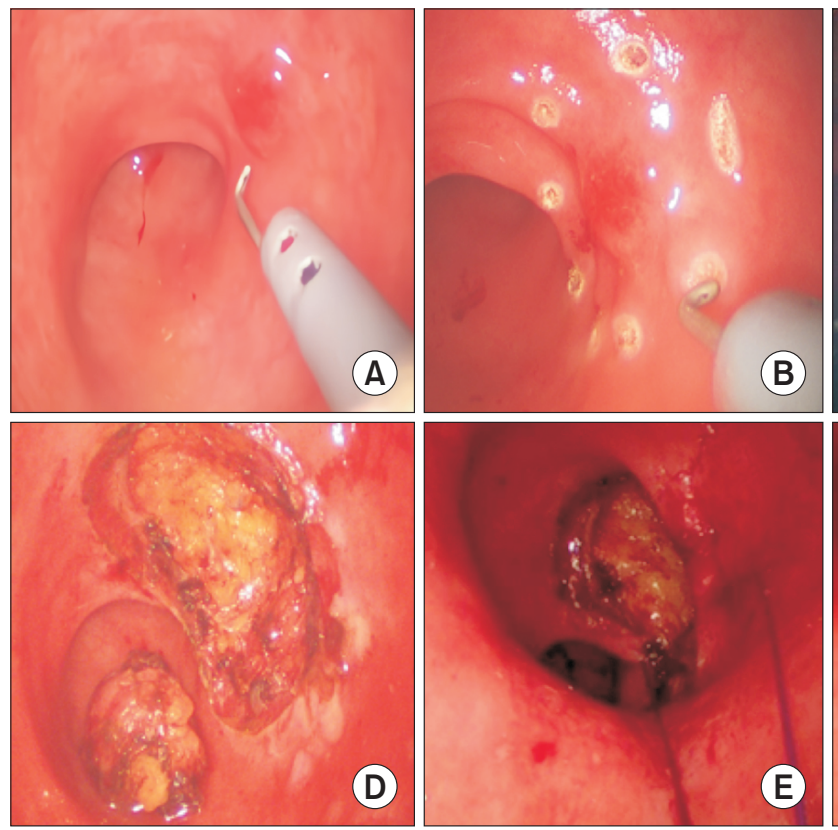

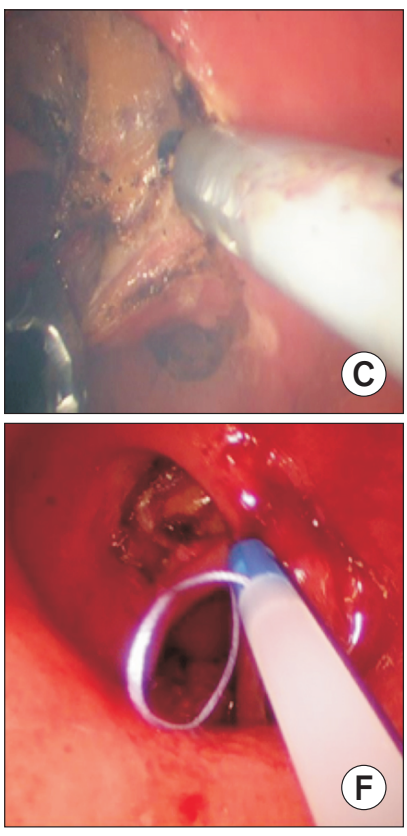

Fig. 1. Procedure of trans-anal minimalIy invasive surgery. (A) $1.2 \mathrm{~cm}$ submucosal lesion at AV $10 \mathrm{~cm}$. (B) Hook cautery usage for marking around the lesion, $(C$, D) Full-thickness excision down to mesorectal fat, $(E, F)$ Closure of the defect with ENDOLOOP®. 
Table 1. Patient characteristics

\begin{tabular}{|c|c|}
\hline Characteristics $(n=30)$ & Value \\
\hline Age, years & $54.4 \pm 17.1$ \\
\hline Male gender, n $(\%)$ & 19 (63.3) \\
\hline Female gender, n $(\%)$ & $11(36.7)$ \\
\hline $\mathrm{BMI}, \mathrm{m}^{2}$ & $24.3 \pm 3.1$ \\
\hline Tumour size, cm & $1.6 \pm 1.6$ \\
\hline Distance from AV, cm & $7.0 \pm 3.1$ \\
\hline Preop endoscopic procedure, n $(\%)$ & $14(46.7)$ \\
\hline Endoscopic mucosal resection & $10(71.4)$ \\
\hline Endoscopic submucosal dissection & $4(28.6)$ \\
\hline \multicolumn{2}{|l|}{ Diagnosis, n $(\%)$} \\
\hline Neuroendocrine tumor & 18 (60.0) \\
\hline Adenoma & $5(16.7)$ \\
\hline Rectal cancer & $4(13.3)$ \\
\hline Rectal stenosis & $1(3.3)$ \\
\hline Rectal sinus & $1(3.3)$ \\
\hline Anastomosis site dehiscence & $1(3.3)$ \\
\hline
\end{tabular}

gone TAMIS for NET (60\%) followed by an adenoma (16.7\%) and rectal cancer (13.3\%). There were single cases of rectal stenosis, rectal sinus and anastomosis dehiscence after low anterior resection included in the study. The latter 3 cases were included as a candidate for TAMIS as the transanal approach of the surgery would be beneficial to the patients considering the nature, size and the location of the pathology.

\section{Clinical outcomes}

The operation related clinical outcome is represented in Table 2. The mean operation time was $52.1 \pm 33.5$ minutes and the mean duration of hospital stay after surgery was $4.3 \pm 4.2$ days. 4 patients (13.3\%) had minor complications after TAMIS with 2 patients $(50 \%)$ had complained of diarrhea, 1 patient $(25 \%)$ complained of fecal incontinence. All patients recovered within 1 week after surgery without any specific treatment. 1 patient (25\%) complained of uncomplicated fluid in the operation bed which subsided without further intervention. There was no dehiscence or stricture of the repair site in all patients.

We had 2 cases $(6.7 \%)$ where the operation was converted to conventional TAE. One was converted due to long operation time of 190 minute caused by hypermotility of the rectum during to repair the resection site (Case 24). The other case was converted due to large lesion $(7 \mathrm{~cm})$ very close from the anal verge $(2 \mathrm{~cm})$ (Case 21), and this was the only case where
Table 2. Clinical outcomes

\begin{tabular}{|lc|}
\hline \multicolumn{1}{|c}{ Characteristics $(\mathbf{n}=\mathbf{3 0})$} & Value \\
\hline Hospital Stay, days & $4.3 \pm 4.2$ \\
\hline Conversion to TAE, $\mathrm{n}(\%)$ & $2(6.7)$ \\
\hline Operation time, min & $52.1 \pm 33.5$ \\
\hline Pathological positive margin status, $\mathrm{n}(\%)$ & $1(3.3)$ \\
\hline Complications, $\mathrm{n}(\%)$ & $4(13.3)$ \\
Diarrhea & $2(50.0)$ \\
Fecal incontinence & $1(25.0)$ \\
Fluid collection & $1(25.0)$ \\
\hline
\end{tabular}

TAE, transanal excision.

the resection margin status was positive pathologically. From our experience TAMIS was suitable and effective in resecting lesions in various locations in the rectum but there were technical difficulties in operating on large lesions located very close to the anal verge. The detailed patient data is represented in Table 3.

\section{DISCUSSION}

Conventional TAE is difficult to adopt for mid to upper rectal lesion due to lack of proper visualization. On the other hand, TAMIS is a comfortable method to visualize the operative field by the use of videoscope through a pneumorectum. In our experience, TAMIS enabled operation on most length of the rectum (ranging from 2 to $15 \mathrm{~cm}$ from AV) apart from the anal verge. However, there were ergonomic difficulties the surgeon encounters when operating the low-lying rectal lesions because of the 'fulcrum effect ${ }^{14}$ where the shorter the distance between the end of a laparoscopic instrument and the port as the fulcrum point, the more force must be used. The excessive force will result in tissue tears. In particular, intracorporeal suturing and knot-tying for the resected site located within $5 \mathrm{~cm}$ of the anal verge were the most challenging but this could be dealt with by using ENDOLOOP ${ }^{\circledR}$ ligatures or $\mathrm{V}$-lock ${ }^{\circledR}$ suture in our experience. Rimonda et al. showed that TAMIS failed to suture the rectal wall effectively in ex vivo setting. ${ }^{15}$ However, in our study laparoscopic dissection under a clear operating field using a videoscope in the pneumorectum allowed complete en bloc resection and this reduced specimen fragmentation rate and local recurrence rate. ${ }^{4}$ We experienced only one patient (Case 21) who had a large adenoma of $7 \mathrm{~cm}$ in diameter had an positive resection margin after TAMIS.

Overall mean operative time was $52.1 \pm 33.5$ minutes. Considering reported TEM average operating times to range from 67 to 79 minutes, ${ }^{16,17}$ our operative time with of TAMIS is 
Table 3. Patients data

\begin{tabular}{|c|c|c|c|c|c|c|c|c|c|c|c|}
\hline No & Age & Gender & Diagnosis & $\begin{array}{l}\text { Distance } \\
\text { from AV } \\
\text { (cm) }\end{array}$ & $\begin{array}{l}\text { Tumor size } \\
\text { (cm) }\end{array}$ & $\begin{array}{l}\text { OP time } \\
\text { (min) }\end{array}$ & $\begin{array}{c}\text { Conversion } \\
\text { to } T A E\end{array}$ & $\begin{array}{c}\text { Preoperative } \\
\text { endoscopic } \\
\text { procedure }\end{array}$ & $\begin{array}{l}\text { Postop } \\
\text { margin } \\
\text { status }\end{array}$ & Complications & $\begin{array}{c}\text { Hospital } \\
\text { Stay } \\
\text { (day) }\end{array}$ \\
\hline 1 & 58 & $\mathrm{~F}$ & NET & 8 & $0.6 \times 0.4 \times 0.2$ & 70 & No & - & - & None & 3 \\
\hline 2 & 22 & $\mathrm{~F}$ & NET & 15 & $1.0 \times 0.8 \times 0.6$ & 60 & No & - & - & None & 4 \\
\hline 3 & 47 & $\mathrm{~F}$ & NET & 10 & $0.9 \times 0.8 \times 0.6$ & 60 & No & - & - & $\begin{array}{c}\text { Fecal } \\
\text { incontinence }\end{array}$ & 3 \\
\hline 4 & 23 & $\mathrm{~F}$ & NET & 6 & $0.3 \times 0.3 \times 0.2$ & 85 & No & EMR & - & None & 3 \\
\hline 5 & 52 & $\mathrm{~F}$ & NET & 10 & $0.4 \times 0.3 \times 0.3$ & 30 & No & - & - & None & 3 \\
\hline 6 & 29 & M & NET & 8 & $0.8 \times 0.5 \times 0.35$ & 45 & No & EMR & - & Diarrhea & 2 \\
\hline 7 & 41 & M & NET & 5 & $0.4 \times 0.4 \times 0.2$ & 43 & Yes & EMR & - & None & 2 \\
\hline 8 & 53 & M & NET & 10 & $0.6 \times 0.4 \times 0.1$ & 40 & No & ESD & - & None & 3 \\
\hline 9 & 34 & M & NET & 10 & $0.7 \times 0.6 \times 0.3$ & 60 & No & ESD & - & Diarrhea & 2 \\
\hline 10 & 53 & M & NET & 3 & $0.2 \times 0.1 \times 0.1$ & 35 & No & EMR & - & None & 2 \\
\hline 11 & 74 & M & NET & 7 & $0.9 \times 0.8 \times 0.3$ & 35 & No & EMR & - & None & 4 \\
\hline 12 & 36 & M & NET & 7 & $1.3 \times 1.3 \times 0.3$ & 41 & No & - & - & None & 3 \\
\hline 13 & 70 & $\mathrm{~F}$ & NET & 7 & $0.7 \times 0.3 \times 0.05$ & 26 & No & EMR & & None & 4 \\
\hline 14 & 58 & $\mathrm{~F}$ & NET & 10 & $0.8 \times 0.7 \times 0.3$ & 20 & No & ESD & - & None & 2 \\
\hline 15 & 66 & M & NET & 3 & $0.4 \times 0.3 \times 0.2$ & 10 & No & - & - & None & 3 \\
\hline 16 & 29 & M & NET & 3 & $0.8 \times 0.8 \times 0.5$ & 21 & No & - & - & None & 3 \\
\hline 17 & 74 & M & NET & 8 & $1.5 \times 1.4 \times 0.7$ & 43 & No & ESD & - & None & 3 \\
\hline 18 & 34 & M & NET & 3 & $0.7 \times 0.6 \times 0.4$ & 23 & No & EMR & - & None & 3 \\
\hline 19 & 61 & $\mathrm{~F}$ & Adenoma & 10 & $3.6 \times 2.2 \times 0.5$ & 80 & No & - & - & None & 3 \\
\hline 20 & 72 & M & Adenoma & 6 & $2.9 \times 2.8 \times 1.6$ & 60 & No & - & - & None & 1 \\
\hline 21 & 62 & $\mathrm{~F}$ & Adenoma & 2 & $7.1 \times 1.2 \times 0.1$ & 60 & No & - & + & None & 4 \\
\hline 22 & 73 & $\mathrm{~F}$ & Adenoma & 10 & $3.2 \times 2.1 \times 0.5$ & 60 & No & EMR & - & None & 7 \\
\hline 23 & 64 & M & Adenoma & 10 & $1.8 \times 1.5 \times 0.4$ & 30 & No & EMR & - & None & 5 \\
\hline 24 & 86 & $\mathrm{~F}$ & Rectal cancer & 5 & $1.8 \times 1.6 \times 0.7$ & 190 & No & - & - & Fluid collection & 7 \\
\hline 25 & 60 & M & Rectal cancer & 8 & $1.0 \times 0.9 \times 0.5$ & 60 & Yes & EMR & - & None & 3 \\
\hline 26 & 50 & M & Rectal cancer & 5 & $1.6 \times 1.6 \times 1.0$ & 25 & No & - & - & None & 4 \\
\hline 27 & 78 & M & Rectal cancer & 7 & $4.8 \times 4.1 \times 0.9$ & 51 & No & - & - & None & 23 \\
\hline 28 & 59 & M & Rectal sinus & 3 & $3.5 \times 2.0 \times 2.0$ & 30 & No & - & - & None & 1 \\
\hline 29 & 53 & M & $\begin{array}{l}\text { Rectal } \\
\text { stenosis }\end{array}$ & 3 & $N / A$ & 95 & No & $N / A$ & $N / A$ & None & 6 \\
\hline 30 & 61 & M & $\begin{array}{l}\text { Anastomosis } \\
\text { site dehiscence }\end{array}$ & 7 & $\mathrm{~N} / \mathrm{A}$ & 75 & No & $N / A$ & $\mathrm{~N} / \mathrm{A}$ & None & 13 \\
\hline
\end{tabular}

NET, neuroendocrine tumor; EMR, endoscopic mucosal resection; ESD, endoscopic submucosal dissection.

shorter than that. Also, TAMIS is proposed to have a gentle learning curve than TEM which has a steep learning curve due to limited space within the proctoscope and the lack of triangulation. $^{18}$ 
In one case (Case 24), it took 190 minutes caused by hypermotility of the rectum during the repair of the resection site. The main factor that prolonged operation was the bowel wall fluctuance and the hypermobility, which interfered with suturing further delaying the surgery. To prevent this situation, Daniel et al. reported the use of intravenous butylscopolamine administered before starting the surgery to reduce bowel spasms and gas-related fluctuation.

Only one patient complaint of fecal incontinence after TAMIS, although the duration of symptom was shorter than 1 week. In the literature, functional outcome data of TEM are inconsistent, but the quality of life after TAMIS indicated low severity of symptoms of anal incontinence. . $^{19-21}$

TAMIS is not our routine practice for early rectal cancers due to the high risk of local recurrence. The postoperative local recurrence rate following local excision for pT1 rectal cancer is in the range of $4 \%$ to $24 \%$, whereas the local recurrence following radical surgery is in the range of $0 \%$ to $7 \% .^{22,23}$ Thus several institutions apply TAMIS in the treatment of wellselected stage I rectal cancer. ${ }^{11,24}$ We considered TAMIS for early rectal cancer in 4 cases of which 2 cases (Case 24 \& 27) was not suitable for a radical resection due to extensive past medical history.

Use of TAMIS in anastomosis leakage has not been studied in the literature but other transanal techniques such as TAE and TEM were used with successful repair of the dehiscence. $^{25,26}$ But the cases of anastomosis dehiscence that was repaired in the literature were dehiscence seen during the primary operation and thus would not have had the difficulty of dealing with hard fibrotic tissue present in the patient (Case 30) we operated on. Although TAMIS provides a good view and is capable of repairing such defect, precaution should be made by the operating surgeon when deciding whether the repair of dehiscence will be successful according to the nature of the tissue.

Most of our TAMIS cases were NET with or without endoscopic resection. The incidence of NETs of the colon and rectum has been increasing in the past decades, thought due to increased screening colonoscopies. ${ }^{27} \mathrm{NET}$ of the rectum that is $\leq 1 \mathrm{~cm}$ in size as well as well-differentiated with World Health Organization grade 1 has very good prognosis. Previous studies have suggested that primary tumour size is the strongest predictor of regional nodal metastasis. ${ }^{28}$ The disease-free survival rate of 49 patients with rectal NET smaller than $1 \mathrm{~cm}$ in size is reported $96.2 \%$ at 53 months after local excision or ablation. ${ }^{29}$ Today, 5 -year survival for stage I rectal NETs with no angioinvasion that are $<1 \mathrm{~cm}$ approach $100 \%{ }^{30}$ There is even no need to follow-up for rectal NETs $<1 \mathrm{~cm}$ by the NCCN guideline. ${ }^{30}$ In this study, TAMIS proved to be a feasible and safe treatment option for rectal NET especially smaller than 1 $\mathrm{cm}$ without evidence of lymph node metastasis. Also, TAMIS was an option for further resection of the remnant lesion after an incomplete endoscopic procedure. A case of delayed local excision of rectal NET after hepatic resection for giant liver metastasis reported the patient has been disease-free for 2 years with good quality of life. ${ }^{31}$

Our study was limited by its retrospective nature, small sample size and short follow-up period. The retrospective design may have caused unintended selection bias of tumors particularly suited for TAMIS. Most of the lesions removed using TAMIS are NET in this study our result suggests that TAMIS may be safe and feasible for NET, but the oncological safety needs to be addressed with further studies. In conclusion, this study shows that the TAMIS is a useful method for local excision of rectal lesion located in mid to upper rectum as well as other rectal pathologies that require the transanal approach. The main strength of TAMIS is the ability to provide a clear visualization of the operating field when compared to other transanal approach techniques especially in the mid to upper rectum, and thus is a safe and feasible option of treatment of rectal pathologies in various locations of the rectum.

\section{ORCID}

Min Kyu Kang, https://orcid.org/0000-0001-5816-5877

Rumi Shin, https://orcid.org/0000-0001-5500-8702

Beong-hoon Sohn, https://orcid.org/0000-0002-2297-5218

Seung-chul Heo, https://orcid.org/0000-0003-3196-5158

\section{AUTHORS' CONTRIBUTIONS}

$\mathrm{RS}$ is the guarantor of the content of the manuscript, contributed substantially to the study design, data analysis and interpretation, and the writing of the manuscript. MKK contributed substantially to the study design, data interpretation, and the writing of the first draft and subsequent revisions of the manuscript. BHS contributed to data analysis and interpretation. SCH contributed substantially to data analysis and interpretation, and the writing of the manuscript.

\section{CONFLICT OF INTEREST}

None.

\section{FUNDING}

None. 


\section{ACKNOWLEDGMENTS}

None.

\section{REFERENCES}

1) Buess G. Review: transanal endoscopic microsurgery (TEM). J R Coll Surg Edinb 1993;38:239-245.

2) Blumberg D, Paty PB, Guillem JG, et al. All patients with small intramural rectal cancers are at risk for lymph node metastasis. Dis Colon Rectum 1999;42:881-885.

3) Endreseth BH, Myrvold HE, Romundstad P, Hestvik UE, Bjerkeset T, Wibe A. Transanal excision vs. major surgery for T1 rectal cancer. Dis Colon Rectum 2005;48:1380-1388.

4) Clancy C, Burke JP, Albert MR, O'Connell PR, Winter DC. Transanal endoscopic microsurgery versus standard transanal excision for the removal of rectal neoplasms: a systematic review and meta-analysis. Dis Colon Rectum 2015;58:254-261.

5) de Graaf EJ, Burger JW, van Ijsseldijk AL, Tetteroo GW, Dawson I, Hop WC. Transanal endoscopic microsurgery is superior to transanal excision of rectal adenomas. Colorectal Dis 2011;13:762-767.

6) Moore JS, Cataldo PA, Osler T, Hyman NH. Transanal endoscopic microsurgery is more effective than traditional transanal excision for resection of rectal masses. Dis Colon Rectum 2008;51:10261030; discussion 1030-1021.

7) Koebrugge B, Bosscha K, Ernst MF. Transanal endoscopic microsurgery for local excision of rectal lesions: is there a learning curve? Dig Surg 2009;26:372-377.

8) Maslekar S, Pillinger SH, Sharma A, Taylor A, Monson JR. Cost analysis of transanal endoscopic microsurgery for rectal tumours. Colorectal Dis 2007;9:229-234.

9) Atallah S, Albert M, Larach S. Transanal minimally invasive surgery: a giant leap forward. Surg Endosc 2010;24:2200-2205.

10) Maglio R, Muzi GM, Massimo MM, Masoni L. Transanal minimally invasive surgery (TAMIS): new treatment for early rectal cancer and large rectal polyps-experience of an Italian center. Am Surg 2015;81:273-277.

11) Albert MR, Atallah SB, deBeche-Adams TC, Izfar $S$, Larach SW. Transanal minimally invasive surgery (TAMIS) for local excision of benign neoplasms and early-stage rectal cancer: efficacy and outcomes in the first 50 patients. Dis Colon Rectum 2013;56:301307.

12) Khoo RE. Transanal excision of a rectal adenoma using singleaccess laparoscopic port. Dis Colon Rectum 2010;53:1078-1079.

13) Lim SB, Seo SI, Lee JL, et al. Feasibility of transanal minimally invasive surgery for mid-rectal lesions. Surg Endosc 2012;26: 3127-3132.

14) Gallagher AG, McClure N, McGuigan J, Ritchie K, Sheehy NP. An ergonomic analysis of the fulcrum effect in the acquisition of endoscopic skills. Endoscopy 1998;30:617-620.
15) Rimonda R, Arezzo A, Arolfo S, Salvai A, Morino M. TransAnal Minimally Invasive Surgery (TAMIS) with SILS port versus Transanal Endoscopic Microsurgery (TEM): a comparative experimental study. Surg Endosc 2013;27:3762-3768.

16) Barendse RM, van den Broek FJ, van Schooten J, et al. Endoscopic mucosal resection vs transanal endoscopic microsurgery for the treatment of large rectal adenomas. Colorectal Dis 2012;14:e191196.

17) Farmer KC, Wale R, Winnett J, Cunningham I, Grossberg P, Polglase A. Transanal endoscopic microsurgery: the first 50 cases. ANZ J Surg 2002;72:854-856.

18) Slack $T$, Wong $S$, Muhlmann M. Transanal minimally invasive surgery: an initial experience. ANZ J Surg 2014;84:177-180.

19) Cataldo PA, O’Brien $S$, Osler T. Transanal endoscopic microsurgery: a prospective evaluation of functional results. Dis Colon Rectum 2005;48:1366-1371.

20) Motson RW, Whiteford MH, Hompes R, Albert M, Miles WF Current status of trans-anal total mesorectal excision (TaTME) following the Second International Consensus Conference. Colorectal Dis 2016;18:13-18.

21) Sumrien H, Dadnam C, Hewitt J, McCarthy K. Feasibility of Transanal Minimally Invasive Surgery (TAMIS) for Rectal $\mathrm{Tu}^{-}$ mours and Its Impact on Quality of Life - The Bristol Series. Anticancer Res 2016;36:2005-2009.

22) Hassan I, Wise PE, Margolin DA, Fleshman JW. The Role of Transanal Surgery in the Management of T1 Rectal Cancers. J Gastrointest Surg 2015;19:1704-1712.

23) Lu JY, Lin GL, Qiu HZ, Xiao Y, Wu B, Zhou JL. Comparison of Transanal Endoscopic Microsurgery and Total Mesorectal Excision in the Treatment of T1 Rectal Cancer: A Meta-Analysis. PLoS One 2015;10:e0141427.

24) Martin-Perez B, Andrade-Ribeiro GD, Hunter L, Atallah S. A systematic review of transanal minimally invasive surgery (TAMIS) from 2010 to 2013. Tech Coloproctol 2014;18:775-788.

25) Beunis A, Pauli S, Van Cleemput M. Anastomotic leakage of a colorectal anastomosis treated by transanal endoscopic microsurgery. Acta Chir Belg 2008;108:474-476.

26) Dapri G, Guta D, Grozdev K, et al. Colorectal anastomotic leakage corrected by transanal laparoscopy. Colorectal Dis 2016;18:O210213.

27) Scherubl H, Cadiot G. Early Gastroenteropancreatic Neuroendocrine Tumors: Endoscopic Therapy and Surveillance. Visc Med 2017;33:332-338.

28) De Felice F, Izzo L, Musio D, et al. Clinical predictive factors of pathologic complete response in locally advanced rectal cancer. Oncotarget 2016;7:33374-33380.

29) Tsang ES, McConnell YJ, Schaeffer DF, Yin Y, Speers CH, Kennecke HF. Prognostic Factors for Locoregional Recurrence in Neuroendocrine Tumors of the Rectum. Dis Colon Rectum 2018; 61:187-192. 
30) Ford MM. Neuroendocrine Tumors of the Colon and Rectum. Dis Colon Rectum 2017;60:1018-1020.

31) Xu G, Wang P, Xiao Y, Wu X, Lin G. Local resection of rectal neuroendocrine tumor with first clinical manifestation of giant liver metastasis by transanal endoscopic microsurgery: A case report. Medicine (Baltimore) 2017;96:e9153. 